\title{
1.5 Updating the ideas of the representatives of the new school of scientific management to improve the educational management of multidisciplinary institutions of extracurricular education
}

Over the past decades, we have seen a number of transformations in the education system and in its separate subsystem - extracurricular education. In our opinion, these radical changes will be one of the most significant events for the life of the future generation. Significant changes are made with the help of external and internal factors. An external factor of transformation is in the discovery of ideas for the transformation of additional, in-depth, non-formal education outside the walls of ordinary schools; an internal factor is a deep study of these ideas and their reflexive implementation in practice. Understanding the pedagogical work of the representatives of extracurricular activities in Ukraine, the implementation of educational management both at the regional, national and international levels - all these are qualitative historical changes that affect extracurricular education in terms of form, processes, and technology of problem solving.

We believe that the current state of educational management development as a separate science and practical activity indicates imperfect procedures and insufficient study of practices for the adoption of new models in management by heads of extracurricular educational institutions. The situation is aggravated by the socioeconomic crisis, which forces the manager of an educational institution to be not just a «teacher of teachers», but also to have an idea of various management functions, which today are extremely difficult for educational activities, because extracurricular education faces the mutual influence of various organizations and shows both the achievements and best experience, and also the shortcomings of educational policies.

Nowadays the educational management of multidisciplinary institutions of extracurricular education goes beyond the existing knowledge of management and it is currently in search of the best theories, concepts and models. To improve this process, it is necessary to conduct an analysis of the ideas presented by the best representatives of the new school of management science, which include such scientists as R. Akoff 
and D. Greenberg [44, c. 2, c. 3], S. Beer [48], L. Bertalanfi [47]. The contribution of this school to management as a science in general and as for the educational management of a multidisciplinary institution of extracurricular education in particular is invaluable. It is explained by the fact that these scientists were the first who noted the concretization of the descriptive process of Management in models and symbols. They directed the solution of problems to the study of quantitative values, statistical data, which provides an opportunity to use new scientific knowledge for practical purposes.

We took into account that the achievements of these scientists are based on the following areas: the use of systematic, procedural and situational approaches, and the management process itself is considered from the point of view of working in the social system. Representatives of the new school of scientific management were the first to use a cybernetic approach, which provided for the widespread use of mathematical methods. In particular, Stafford Beer, revealing management issues in cybernetic terms, formulated the idea of general principles for managing any probabilistic system: a computer as an inanimate complex system; an organization in which people interact - a complex living system. S. Bir's idea is fundamental regarding the four reasons for recognizing the system: 1) combination within a certain experience; 2) survival in time by a certain appropriate definition of continuing identity; 3) achievement of goals is regulated by prescribed rules of activity that are acceptable for continuing existence; 4) assimilation of one's own experience, self-regulation of learning, adaptation and evolution processes [48, p. 167]. The idea of an English scientist about the need to draw up concepts, develop mechanisms and laws that should be effective in designing or redesigning systems for management by managers is still relevant. The scientist wrote: «if cybernetics is the science of control, management is the profession of control. Every manager ... faces identical problems. He faces the realization that maintaining a viable system is much more difficult than he personally can understand. And the beginning of wisdom in management at any level is to understand the viability of systems that are mostly self-regulating and even self-organizing» [48, c. 168]. 
The most important concept of educational management is the viability of the system. At the same time, S. Beer appeals to the following main characteristics: 1) the results of activities should be under control: we need to know how to do this, manipulate the system so as to get the desired effect; 2) the system as a whole should be ultra - stable, because instability is the main symptom of an organization that is poorly managed; 3 ) for the growth and evolutionary development of the system, it is necessary to generate innovations that make you learn and adapt, increase «muscle» tone [48, p. 173]. In our opinion, this argument is quite balanced and can be extrapolated to the practice of managing multidisciplinary institutions of extracurricular education.

It is known from scientific sources that L. Bertalanfi is one of the outstanding scientists who started the study of general systems theory. He pointed out that there are certain problems in any field that can be ignored by classical science. He mentioned: «There is an urgent need to extend the means of science to those areas that go beyond physics and have specific features of biological, behavioral and social phenomena. This means that new conceptual models must be built. Each science is in the broad sense of the word a model, that is, a conceptual structure that aims to reflect certain aspects of reality» [47, p. 23]. Given this opinion, we point out that the issues of improving the educational management of multidisciplinary institutions of extracurricular education should leave the field of view of purely practical activities and acquire a transformation, a new structural description that should streamline the process of managing creative people who in their activities should lead the future generation to axiological guidelines.

General systems theory provides an opportunity to describe the educational management of multidisciplinary institutions of extracurricular education through such concepts as "integrity", "organization", "teleology", "direction of movement or functioning". These concepts are extremely important tools for scientific analysis, which involves rethinking of management procedures and building new models of educational management. In other words, we are talking about a new vision of extracurricular education, inventing its ideal future. The changes should come from 
rethinking the status of educational management. The need to introduce a systematic approach to management in general is noted in the book «Management of the XXI century» (by Russell Ackoff). The author deduces the position of management as a fundamental function of the manager. According to his opinion, the manager should manage not actions, but interactions: «1) the interactions of those divisions and people who he is responsible for; 2) the interactions of his divisions with other divisions within his organization; 3 ) the interactions of his divisions with other organizations or their divisions related to the environment» [46, p. 19].

Speaking about social systems (corporations, educational institutions, etc.), Russell Akoff pointed out that the management of such systems should be subjected to certain rules, since each social system has a corresponding goal. That is, a multidisciplinary institution of extracurricular education, as a social system, has a clearly defined goal and, accordingly, the functioning of this institution occurs through following this goal. In the management of such an institution, it is important to rely on the principle of autonomy, which enriches the professional activity of teachers, and at the same time is the beginning of the transformation of the world of this type of Education.

In working with social systems, as Russell Ackoff proved, techniques for managing «organizational» systems are useful. A democratic organization, according to the author, cannot be modeled from the point of view of an "organizational" system, since such modeling will not be able to take into account the ability of individual parts to make a certain choice. Autocratic systems will experience a number of difficulties (if the number of its members increases, the number of technologies that provide solutions to their problems increases and the variety of requirements imposed on them increases).

In other words, the complication of situations around the functioning of extracurricular institutions, the uncertainty of the prospects for out-of-school education, the introduction of new technological solutions - that is all that accompanies the process of out-of-school education today, thus forcing us to reconsider the issue of educational management in a new way. Appropriate in this case is the pattern that was 
derived by the scientist: «the better those who are managed know how to perform their functions, the less effective is autocratic control on the part of those who manage them» [46, p. 38].

Consequently, in contrast to the autocratic management of a multidisciplinary institution of extracurricular education, there should come a system of democratic governance, where all subjects involved in providing and acquiring the necessary competencies for life will be allowed to have the opportunity of choice and freedom.

Autonomy, freedom, and the ability to choose are the main values that the head of a multidisciplinary institution of extracurricular education should take into account. These ideas are based on the correct statement of Russell Ackoff and Daniel Greenberg about ideal educational institutions. In the book «Transformation of education», the authors pointed out that ideal educational institutions should be autonomous and at the same time have the funding that is necessary for their existence. Only collective decisions and the realities of the environment can impose some restrictions, but self management is the main principle for the development of an institution. In their opinion, education performs two functions - external and internal. The external (instrumental) function, according to Russell Ackoff and Daniel Greenberg, is to encourage and promote the development of students, help them become useful to others and gain independence in society. That is, this function helps to develop the ability to learn what students need to know in order to make a personal contribution to improving the viability of society. The internal function of education is to provide students with the ability to enjoy activities that do not have instrumental value, but meet cultural needs, entertainment and recreation needs, namely: enjoying music, art, literature, games, etc. According to them, getting pleasure from work, pleasure from studying is one of the universal values in the life of a modern person in the post-industrial world [45, p. 15-17]. And all this is true, because the transformation of extracurricular education should begin with activating the process of understanding its actual goals. The goal in institutions of extracurricular education should be in acquiring competencies, the real learning process, and not the teaching process. That is why the focus of attention should be shifted to the very essence of the educational process, that 
is, to include the necessary competencies in the multi-channel process of obtaining information by pupils to formalize the overall picture of the world, create characteristic qualities and humanize personal traits, and so on.

Taking these ideas into account, we emphasize the potential for revealing the universal ideal content of extracurricular education, which, according to the law of Ukraine «About extracurricular education», «is aimed at developing the abilities and talents of pupils, students and listeners, meeting their interests, spiritual requests and needs for professional identification». We emphasize that extracurricular education in Ukraine is part of continuing education, in such institutions scientific knowledge should be provided, «skills according to interests» should be formed, «the needs of the individual for creative self-realization and intellectual, spiritual and physical development» should be provided, as well as preparation «for active professional and social activities» should be carried out, «conditions for social protection and organization of meaningful leisure activities in accordance with the abilities, talents and health status of pupils, students and listeners» should be created. That is, to update the purpose of the activity of a multidisciplinary institution of extracurricular education, such conditions should be created so that each pupil can cover the unity of knowledge that is valuable to him, and each teacher can turn this knowledge into a certain and understandable system that makes up the real world. In this regard, Russell Ackoff and Daniel Greenberg agree that there are two different worlds in which the concept of «education» is used differently. In one - standardization, learning according to the model, and in the other - the transfer of wisdom: «one world consists of schools, colleges and universities that make up our educational complex, in which standardization prevails. In this world, the megastructure of industrial training seeks to produce identical samples of products, which are called «people who were educated for the XXI century». The second world is a world of information, knowledge and wisdom, in which the real population is located, and is not in the prison, as in schools. In this world, learning takes place as always, and teaching consists in transmitting wisdom to free listeners» [45, p. 27]. The process of passing on wisdom to free listeners contradicts existing approaches, where a pupil must thoroughly study the material that 
others have talked about. Control and credit procedures also contradict the real world. So, the material should be firmly memorized and reproduced during the exam without any help, in complete isolation: «schools and universities at each level try to determine, if not measure, how much knowledge students have learned through exams and tests... At the same time, students should work in complete isolation ... And such a scenario is diametrically opposite to what is required of them in the real world» [45, p. 41].

We emphasize that multidisciplinary institutions of extracurricular education have a world of «information, knowledge, wisdom», which is different, in contrast to a regular school, where there is a certain set of competencies that must be obtained as a tool for survival in the world. In our opinion, in multidisciplinary institutions of extracurricular education, other competencies are acquired - transversal, which are necessary for real life. It is important to acquire the ability to use the obtained knowledge together with friends and translate it into specific real situations, and this, in our opinion, should be evaluated and appreciated. And the wider the list of profiles in such an institution, the more opportunities students have for Poly-subject use of new information to make personal growth possible. That is why it is legitimate to say that it is outside the walls of the classroom that education is revealed as what is needed in the real world, and that knowledge, in contrast to instrumental knowledge, is valued much more, because it is obtained for a full life.

In the context of improving the functioning of multidisciplinary institutions of extracurricular education, it is impossible not to touch on the ideas of autocracy and democracy in educational management. Let us point out a sharp criticism of autocracy in the management of educational institutions in many countries. Among the main characteristics that prevent a breakthrough in extracurricular education as a sphere of creating humanity, we can name the following: hierarchy, a clear scheme of control, unlimited power of each level over the level below, finding students at the lowest level of the hierarchy, the lack of regular means of appeal, the publication of rules and instructions without the need for their discussion or approval, and so on. These characteristics hinder the self-realization of subjects of extracurricular education, their full disclosure of spiritual, mental, and social potential. Russell Ackoff and Daniel 
Greenberg were among the first to point out the laws of the autocratic system of Educational Management. They described the results of autocracy in educational management as follows: the entire education system is riddled with resentment and hatred, and at every level a lot of effort is spent breaking or avoiding the rules. Large groups of pupils do not do what is interesting and meaningful, but what is necessary from the point of view of teachers: «the architects of our educational system have obviously forgotten about one big rule of political democracy: laws are created with the consent of those who they will be applied to, the management with the consent of those managed, enjoys respect and a high level of compliance with the rules, which no other system can achieve, even one that is supported by mass terror. The law that you helped create, you would be the last to break» [45, p. 85].

Consequently, the inability to be free in an educational institution, that professes an instrumental approach, devalues the educational process itself. It forces those who are managed to commit violations, since the most important thing is violated - the student's right to a decent choice. In the future, it may lead to a disregard for the values of a democratic society, since, as the authors mention, when the management is carried out autocratically, it «deprives students of the opportunity to learn democracy from their own experience. » It causes further problems in society, because students are «not ready to participate in democratic organizations...» [45, p. 109].

So, educational management in multidisciplinary institutions of extracurricular education should be characterized by the prospect of spreading a democratic system of relationships, which is guided by the value of each person's free choice. Classes in such institutions are held in a completely different way, because students have an opportunity to choose the program, the course that they want to study, which really meets cultural needs, the needs for pleasure and recreation. Students socialize and form themselves as a valuable, autonomous person with positive human qualities without using given patterns.

It is appropriate to improve the educational management of multidisciplinary institutions of extracurricular education by revealing the main elements that will create an ideal educational environment. Let us list the positions that were identified by 
American scientists: the learning process is determined by self-motivation and selfgovernment; all interests have the same status; students' academic performance is determined only by their self-assessment; there is freedom to turn to external assessment; the creation of student groups (classes) based on common interests; there are no artificial differences between students and teachers; all members of the education community take an active part in regulating the learning process and various activities. Individual freedom is the main value in such a learning process, and students should be prepared for activities in a democratic world. The main feature in management is participation, and the value is respect for the rights of everyone: «Rules of conduct, use of property, cost planning, hiring employees, arbitration procedures everything is determined by discussions and decision making in democratic legislative bodies of the school» [45, p. 149].

Russell Ackoff and Daniel Greenberg do not ignore the existing problems of additional education, which should be built on «competency support» programs which take into account the real picture of the world. The authors put forward special requirements for the content of such programs, namely: providing opportunities to discuss, taking into account the cultural environment, constant updating of information, interaction with users of such programs, etc. [45, p.158]. We fully agree with the authors' opinion that over the time there should be more and more of such programs, and this idea gives a certain impetus to the teams of multidisciplinary institutions of extracurricular education in our countries, which today have an incentive to develop the setting up of creative author programs by specialists. These programs should complement instrumental education, using cultural and leisure elements that are interesting for the person himself/herself.

In this context, it is appropriate to distinguish between the roles of heads of institutions of extracurricular education. There is still an opinion in the society as to the difference in the content of the concepts of «leader», «manager», «administrator». Here we get in the work of Russell Ackoff and Daniel Greenberg a clear distinction between the outlined roles of managers, their significant difference. So, to administrators the authors refer those who manage others to achieve goals using some 
means. At the same time, both goals and means are determined by a third party (managing a group of clerks who perform routine tasks such as taking orders, preparing to receive orders, etc.). To managers the authors refer those who manage others to achieve the goals set for them using means. The means are chosen by the manager himself, although many of those who are called managers are actually administrators. The authors deduce the following pattern: the more autocratic an organization is, the fewer managers and more administrators it has. The authors refer to leaders those who lead others to achieve goals using means, and both goals and means are chosen by those who lead the leader, that is, they follow the leader voluntarily. In case when the leader is not followed voluntarily, because of his power and the ability to punish for disobedience, he is considered to be a commander. Leadership, according to Russell Ackoff and Daniel Greenberg, is a practice that cannot be taught. This is a special talent and skill that cannot be taught, but only corrected and allowed to develop [45, p. 129].

Also, according to Russell Ackoff, the management of the social system will be unsuccessful if you use the organizational command and control function of management. And it should change the approach to management itself: «system management is interaction management. It is based on the knowledge that the system is not the sum of the work of its parts, but the product of their interactions with each other and with the external environment. There comes the authority of the leader as the replacement of supervision, orders and teams» [44, p. 437].

Among the main management models used in various organizations, the author attributed reactive (managing by the «parent»), passive (managing crises) and preventive (overcoming problems that may appear due to constant planning of actions that should reach the goal). At the same time, the author promoted a new model of interactive management, which will allow creating the future not by planning actions that will allow somebody to reach the goal, but on the contrary - from the goal of an imaginary ideal to the present. That is why it is very important for a manager, according to Russell Ackoff, to have a projection of the future of the organization: «the projection of the future reveals not only what can happen, but also suggests what can be done to avoid approaching it. This gives the organization the ability to control a significant part 
of its future or at least influence it. If it does not plan the implementation of its future it will become an object of interference from others». [46, p. 107].

To summarize the ideas, we can get a structuring of knowledge for the educational management of a modern multidisciplinary institution of extracurricular education on the following issues: what aspects of the functioning of the institution can be interfered with, what procedures can be reworked or developed again? How can the structure of the institution be improved, and how can the rules used by teachers be improved? These positions, in our opinion, still need to be justified in each situation, according to the specifics of the work of the institution.

In general, a critical analysis of the developments of the new school of scientific management indicates that it is possible to synthesize several rules of educational management in institutions of extracurricular education. So, in a multidisciplinary institution of extracurricular education, the head needs to have specific knowledge of educational management and be able to promote pedagogical activities, motivate teachers to work with students with creative inspiration and try to develop them. In other words, educational management should be built in such a way to make the organization be self-managed and self-regulated. Since teachers have a certain level of education according to their profile, the manager should focus them on improving their knowledge and improving the educational process with students every day. It is also important to manage the interaction of teachers in the institution but not the activities that are created by teachers themselves with students. In other words, the head of a multidisciplinary institution of extracurricular education should manage the interaction of employees in the institution and their interaction with representatives of external organizations.

Planning the activities of teachers should be done, having an imaginary ideal - a model of the future multidisciplinary institution of extracurricular education. This approach will help to reveal new forms and methods of work, new ideas and new directions for development. Such planning includes several positions, namely: the mission declaration, which defines the ideals and goals of a multidisciplinary institution of extracurricular education, which will allow the institution not to survive, 
but to develop and flourish; determining the main properties of the institution, its ideal and unique behavior in society, cultivating participation in the management of the pedagogical process of all subjects (both pupils, their parents and people replacing them, and teachers themselves); creating such a project of the institution, which is considered ideal for expressing creative ideas of both teachers and pupils; creating the fastest possible course of action that can get closer to the ideal project of an educational institution - an institution that is trusted, respected, constantly improving, learning new and progressive things, and so on. For such an institution, it is necessary not only to reform, but also to transform, to show a spirit of autonomy, to be open to ideas, which will allow achieving multidirectional mutual agreement.

Multidisciplinary institutions of extracurricular education will not have the ability to provide high-quality educational services that form transversal competencies if representatives of educational management cannot adapt to the requirements of the XXI century. That is why the management system that actualizes the processes of achieving the ideal should focus on gaining independence, order, and presentation. In our opinion, in the near future, the heads of institutions of extracurricular education will be interested in creating such ideal management models that will allow them to make their own decisions. For this purpose, nowadays in such institutions there are processes of self-organization of professional life, which significantly enriches the experience of creating an original worldview. In our opinion, due to such educational management the future generation will not be limited to instrumental education, but will learn to comprehend, experience and create. 